\title{
DEVELOPING ARGUMENTATIVE LITERACY AND SKILLS IN ESP STUDENTS
}

\author{
Kira V. Gudkova \\ St Petersburg University, Russia
}

\begin{abstract}
The paper deals with the problem of argumentation literacy in the field of university ESP teaching. It presents the analysis of arguments that university students put forward while writing argumentative essays as part of their final English tests. The analysis concerns essays written by students at various levels of command of English, namely B2 and $\mathrm{Cl}$ levels. The analysis is aimed at showing connection between students' language ability and their argumentative ability. The findings obtained stress the necessity to develop in ESP students argumentative literacy, that can be considered as one of the main soft skills needed in all spheres of professional and academic life.
\end{abstract}

Key words: argumentative literacy, soft skills, levels of command of English

\section{INTRODUCTION}

The modern world is changing at a very high speed and thus the adaptation to the changes is needed from both educationalists and students who have to critically review their approaches to teaching and learning. This is especially important in the field of teaching English for specific purposes that has become one of the prominent areas of teaching English in Saint Petersburg State University. Namely, the ESP English has become the main priority at the Faculty of Foreign Languages that provides instruction in foreign languages for the students of all faculties at the university. It should be noted that ESP teaching goes beyond teaching just language, it also involves teaching skills, stresses the importance of writing for the audience, and the developing students' awareness of communicative strategies involved in the activities that they will undertake. (DudleyEvans 1998). The ESP main point is that English is not taught as a subject separated from the students' real world, instead it is integrated into their world, it is integrated into the areas important to the learners. Thus, ESP English concentrates on language in context, students are taught how to use English in the areas related to the majors, how to use English in order to perform job-related functions. These functions cover a wide range of areas such as business, medicine, law, management, computer science, engineering, tourism. The students are taught how to employ English as an instrument to help them in

Submitted December $27^{\text {th }}, 2020$, accepted for publication March $4^{\text {th }}, 2021$

Corresponding author: Kira V. Gudkova. St Petersburg University, 11 Lieutenant Shmidt Emb.,

St Petersburg 199034, Russia, Russia|E-mail: gudkovakira@bk.ru 
their future professional lives. In this way some soft skills such as communicative skills, team working and others are formed.

The document that emphasizes the importance of skill-and-competence oriented approach to teaching is The Common European Framework that provides a common basis for the elaboration of language syllabuses, curriculum guidelines, etc. across Europe. It describes in a comprehensive way what skills language learners have to acquire in order to use a language for communication and what knowledge and skills they have to develop to be able to act effectively. According to the CEFR, language use, embracing language learning, comprises the actions performed by persons who as individuals and as social agents develop a range of competences (CEFR 2001).

Competence-based teaching has got its further developments in soft skills developmentoriented approaches that are being employed by modern educationalists. The soft skills are defined as the skills that shape how you work on your own and in a team of colleagues. The basic soft skills that are considered to be of great importance in modern life are the following: effective communication, teamwork, creativity, open-mindedness, critical thinking, problemsolving. All these skills might be necessary in many professional areas such as medicine, law, journalism and many others.

One of the important soft skill that is needed in all spheres of our life is the ability to express one's point of view and present proper arguments to defend it. These abilities lie in the domain of argumentative literacy.

\section{ARGUMENTATIVE LITERACY}

It is not an overstatement to say that people express their opinions and try to persuade other people both in their academic and professional life. Whether students try to persuade their teachers to let them hand in the essay past the deadline or they need to prepare a presentation on a certain topic they employ argumentation even if they do this naturally without thinking about the rules and theoretical aspects of arguing. Doctors employ argumentation when they try to persuade their patients to take a certain course of treatment, business people use argumentation when they negotiate with their partners and competitors. Literally in every sphere of life people employ argumentation as naïve arguers in the sense that they do so without thinking much about the theoretical grounds of arguing. But not only do people employ argumentation to persuade other people they are also exposed to other people's arguments.

But persuading other people is not limited to the academic and professional spheres. English is also used as a means of communication and consequently as a means to express one's views and ideas in social and personal spheres.

That is why we think that it is of great importance to develop in ESP students not only language proficiency but also argumentative foreign language literacy that comprises the ability to present a view point in a foreign language (English in our case) drawing on linguistic devices, to put forward arguments for or against a particular standpoint, to sequence arguments in a logical way and to present arguments organizing them in argumentative structures. Argumentative literacy also involves the development of a range of soft skills such as: analysis, observation, reasoning, persuasion, decision-making.

It should be noted that many students already possess some or all of these skills and employ them to cope with the problems in everyday life. However, as S. Cottrell notes 
the more advanced the level of study, the more refined these skills need to be'. (Cottrell 2011). The better skills are crucial in dealing with complex problems and projects both in academic field, professional, personal and social areas of life.

It can be said that practical argumentative literacy has mostly been developed and practiced in legal and business schools. Foreign languages in most cases have served as a subsidiary instrument used for verbal socializing. Moreover, the model of the adult world reflected in the language is connected with certain stereotypes, which should be taken into account and are relevant for argumentation literacy (Goudkova, Tretyakova 2014).

Second and foreign language teaching is often based on the assumption that learners have already acquired some knowledge of the world sufficient for the purpose of participating in argumentative dialogue. This is, however, not always the case and we think that is definitely not the case when we are talking about argumentative literacy of the learner of a foreign language. It is really difficult to put your message across to other people in a foreign language and far more difficult to convince them.

The learner may well argue in his/her mother tongue and we tend to extrapolate his/her ability into a foreign language. Understanding the stereotypes and the fact that people communicate and listen differently is a part of argumentation and language teaching.

As J. Harmer noted 'language teaching... reflects the times it takes in. Language is about communication... Teaching and learning are very human activities; they are social just as much as they are linguistic' (Harmer, 2011, p. 9)

\subsection{Argumentative literacy criteria}

In order to understand how well students can argue in English we carried out the analysis of arguments that university students put forward while writing argumentative essays that are an obligatory part of their final test in English. The essays written by the students with different levels of command of English (B2 and C1) were analyzed and comparative analysis was conducted in terms of the arguments that were provided. The findings obtained demonstrate some common patterns and reveal the fact that there is a link between the argumentative competence and language proficiency.

First, let us look at the criteria for two levels (B2 and C1) that focus on argumentative competences.

CEFR criteria at the target levels B2 and $\mathrm{C} 1$ are the following:

B2 students can write an essay or report, which develops an argument systematically with appropriate highlighting of significant points and relevant supporting detail. They write an essay or report which develops an argument, giving reasons in support of or against a particular point of view and explaining the advantages and disadvantages of various options. They can synthesize information and arguments from a number of sources. They possess a sufficient range of language to be able to give clear descriptions, express viewpoints and develop arguments without much conspicuous searching for words, using some complex sentence forms to do so.

C1 students can select an appropriate formulation from a broad range of language to express him/herself clearly, without having to restrict what he/she wants to say. They can write clear, well-structured expositions of complex subjects, underlining the relevant salient issues. They can expand and support points of view at some length with subsidiary points, reasons and relevant examples. 
Thus, according to the CEFR argumentative literacy is required at both levels of command of English but the requirements differ. Some important distinctions of argumentative competences at $\mathrm{C} 1$ level are that unlike $\mathrm{B} 2$ students $\mathrm{C} 1$ students should be able to produce complex argumentation (to defend not only the standpoints but to support arguments with sub arguments) and to argue about complex concepts.

\subsection{B2 students' argumentative ability}

Let us look first at argumentative ability demonstrated by B2 students. The analysis shows that students presenting their essays at B2 level demonstrate some argumentative abilities and competences. They can indicate standpoints and support them with arguments. They employ the limited range of language to express standpoints. The examples of the expressions are the following:

In my opinion, I personally think, I agree, I consider, I believe, I think, I feel, as far as I am concerned, my personal opinion is, from my point of view.

The results demonstrate that the most common way to indicate a standpoint at this level of the English language proficiency is to indicate the standpoint explicitly by using personal pronouns and explicit linguistic markers as can be seen from the given examples.

The analysis also shows that at this level of language competence students largely employ two main types of arguments: the first type covers mainly personal or utilitarian, and beneficial arguments. The arguments are utilitarian and beneficial in the sense that the students make an appeal to the concepts of "usefulness and benefit", to the things that will be useful and beneficial for them. Thus, it should also be noted that the arguments are closely connected with the personal life experience of the arguer.

Let us look at the examples of such arguments. The standpoint that is defended is expressed explicitly with the clear linguistic marker. To defend the standpoint three arguments are put forward. It can be seen that All arguments cover issues that are personal and connected to the students' life experience.

Standpoint: In my opinion, people should communicate face to face.

Argument 1. A human will feel himself better if he communicates really not with Internet.

Argument 2. Live communication will help us to understand other people, their problems, interests.

Argument 3. By this way you can find friends easier and faster.

The second type of arguments provided includes arguments to popular opinion, to what is accepted in society and that is why is considered to be good. This type of arguments can be illustrated with the following examples:

Standpoint: The Internet is very useful thing.

Argument 1. It can help us to find information,

Argument 2. It connects people around the world, we can chat how much we want.

The important conclusion that can be made is that given examples show that at this level of English proficiency the students argue from their own experience. This inability also reveales itself in the concepts to which they appeal: the concepts such as life experience, independence, success, self-confidence that present some verbal stereotypes that belong to their picture of the world.

All these examples of utilitarian argumentation reveal that at B2 level students (in the majority of cases) cannot alienate themselves from their personal foreign language 
experience and put forward arguments that are closely linked to their knowledge of the world. Thus, they draw heavily from their knowledge of the world that was formed mainly by their environment (school, family, friends etc.). B2 students prefer to express their standpoints explicitly or present a certain standpoint as a generally accepted idea such as 'some people think'. B2 students act as 'naïve' arguers and make use of the tools they would have used arguing in their mother tongue, for it seems safer to stick to generally accepted ideas.

\subsection{C1 students' argumentative ability}

The arguments employed by $\mathrm{C} 1$ level students differ from those used by B2 students in several aspects. Firstly, the conducted analysis of the essays written by $\mathrm{C} 1$ students shows some definite ability of $\mathrm{C} 1$ students to alienate themselves from the personal experience and produce more abstract and impersonal arguments. Secondly, these types of arguments are presented in a more orderly way and they are more explicit. Thirdly, standpoints are becoming more varied and the point of view is expressed more eloquently. Although the functional register of verbal stereotypes is still egocentric as in utilitarian argumentation, the indicators reflecting introductory level of argumentation show the language confidence of the speaker. Some of the examples of the linguistic markers that are employed to introduce standpoints are: I cannot deny, I would like to say, that's why I am sure etc.

It should be noted that $\mathrm{C} 1$ students more often than $\mathrm{B} 2$ students introduce the standpoints without explicit verbal indicators. And $\mathrm{C} 1$ students often employ compound sentences to formulate standpoints. The example of such a way of presenting a standpoint is given below.

Nowadays globalization not only affects world economy and culture but also changes people's everyday experiences.

The analysis also reveals that like B2 students C1 students employ utilitarian arguments but these arguments differ from those provided by B2 students. $\mathrm{C} 1$ students also make an appeal to the usefulness but to the usefulness for the community and society in general rather than to the usefulness for themselves. Thus, at this level it can be noted that utilitarian arguments become more impersonal. This can be illustrated with the following examples:

One more argument for globalization is that it benefits everyone, not only big corporations but also people in developing countries, as it provides them with job places.

It (globalization) offers new opportunities for travel, work and education and of course for communication.

In terms of logical sequencing of arguments, the analysis shows that $\mathrm{C} 1$ students demonstrate the ability to use regressive presentation, that means that the speaker puts forward arguments and then expresses his/her opinion (which is not the case with B2 students' argumentative ability who prefer the progressive presentation that is to express the standpoint first and then support it with arguments). The example of a regressive structure is provided below.

Companies tend to become more productive and competitive thereby raising the quality of goods, services and the standards of living, that's why I am sure that term globalization is definitely about progress.

It also should be noted that $\mathrm{C} 1$ students often employ opposite concepts to present their arguments thus directing the vector of argumentation to the positive concepts when defending a standpoint and to the negative concepts when putting arguments 
against the standpoint. Here are arguments that students put forward arguing for and against globalization.

Arguments for:

When the nations have "one world, one vision", the same political and economic interests, it helps them to live in peace - appellation to the concept of "peace".

Globalisation encourages better standards for the environment - appellation to the concept of "environment protection".

In both arguments the students make an appeal to positive concepts such as "peace" and "environment protection". If we look at the arguments that were employed to argue against globalization, we will see some negative concepts.

Argument against:

Globalisation results in destruction of cultural diversity.

The negative concept to which the arguer appeals is the concept of destruction.

Thus, we can specify the following features of $\mathrm{C} 1$ student's argumentative ability: a regressive presentation of argumentation, alienation from personal experience in utilitarian argumentation scheme, a greater number of verbal expressions reflecting introductory level of argumentation and the use of opposites as a specific pattern.

The analysis of B2 and C1 students' essays shows that students writing in English may know the basics of argumentation but they cannot use arguments properly, as they are not proficient enough in the L2 language. They start using proper arguments when they become more skilled in the language and the results show that that is mainly achieved at $\mathrm{C} 1$ level.

It can also be noted that students act as naïve arguers because they lack some basics of argumentation literacy. They produce their arguments for the most part on intuition, drawing heavily from their knowledge of the world, which tells more about the writer than about effective arguments.

Taking everything into consideration it should be stressed that the development of argumentation literacy should be incorporated into the ESP curriculum to provide students with basic concepts and argumentative practices. Argumentative ability appears to correlate with innate properties of the student's mind and the language proficiency. The more advanced in the language (English) students become the more independent from their personal experience they grow and the more impersonal their arguments become. Thus, the higher language competence is the more abstract arguments are used.

\section{ARgumentative Literacy SKiLls to Be DeVEloped}

New requirements for English as a foreign language have recently been adopted for university students in $\mathrm{SPbU}$. According to these requirements all university graduates should possess B2 in English. Thus, the target level for university graduates is upperintermediate. To officially confirm this level of language proficiency students are supposed to sit the final test that includes several parts. One of the writing parts is the opinion essay. The speaking part of the final test includes the task to take part in an argumentative dialogue or a debate on a given topic with the examiner. Here is the example of the exam speaking task.

You have to discuss which one programme of the City Development plan would be the most important for young people today. You have three options to choose from: 
- free Wi Fi in public places,

- volunteer litter clean-up events,

- communal public bikes.

The students are supposed to discuss all options with the examiner and come to the conclusion. One of the skills to be tested is the ability to support the opinion with arguments. The assessment criteria take into account the quality of the arguments provided by the students and logical organization. Thus, all university graduates are supposed to possess argumentative literacy and be able to produce proper arguments both in written and in oral forms.

Thus, it seems of great importance to develop argumentative literacy in students and to incorporate some argumentative practices into English courses.

Argumentation is a two-way process, a kind of dialogue between you and those whose beliefs and behaviour you want to change. One of the definitions states that 'argumentation is a form of... communication relying on reasoning... to influence belief or behavior through the use of spoken or written messages (Rybacki and Rybacki 1991). Like other forms of communication, argumentation is a matter of choosing what to say and how to say. In other words, it is a matter of using some knowledge about arguing and employing argumentative skills.

At this point it should be noted that there are two important domains in which argumentative skills should be taught and developed. The first domain covers the skills to build correct arguments, to understand what arguments are, to distinguish arguments from other statements such as explanations, descriptions and from supporting ideas, to link arguments in a logical way. All these skills are necessary to provide a good line of reasoning both in academic and professional spheres.

The other domain covers the abilities to understand other people's argumentation. And the skills to be taught are the following: detecting bias, identifying the flaws in people's reasonings, understanding other people's opinions. These skills are also of great importance in building the resistance to manipulation. If we can identify that the wrong arguments are being put forward and the biased language is employed in communication, if we can detect the flawed structure of argumentation (whether the speaker or the writer does so intentionally or unintentionally) we are immediately able to detect that we are being manipulated, that is we are able to detect the biased argumentation.

\subsection{Skills to build the correct argumentation}

As D. Walton emphasizes argumentation is a practical skill that needs to be taught through the use of realistic examples of arguments of the kind that people encounter in everyday and professional life. (Walton 2006). But argumentation is also a critical attitude that is most useful when we are in a situation where we need to make a thoughtful decision.

The most common applications of argumentation occur in situations where the ideas to be implemented need some support from other people. Thus, we need not only to communicate the idea but also to provide good reasons why this idea should be accepted.

That is why ESP students should be taught to phrase the opinion, to link arguments in a logical way, to analyze the target audience.

Argumentation theorist indicate that there are basic structures that are normally combined in various patterns, which happens in real life argumentation (Eemeren and Grootendorst 1992). All the main structures are characterized by linguistic indicators that point out a certain 
line of reasoning (Eemeren, Houtlosser and Henkemans 2007). It might be useful to include practicing these structures and thus to develop argumentative skills.

\subsection{Skills to evaluate other people's argumentation}

The other domain of arguing involves the analysis of other people's argumentation. One of the skills to be taught (that is also important while building one's own line of reasoning) is the distinguishing arguments from non-arguments. When considering an argument, it is easy to be distracted by surrounding messages such as description, explanation, summary that can be confused with arguments.

Another important skill to be developed in ESP students is the identification of flawed arguments in other people's reasoning. There are two situations in which people can use flawed arguments. First, the simply do not recognize that the arguments they put forward are flawed. And this happens very often. Second, people use flawed arguments deliberately for they want to manipulate other people, to make them change their behaviour so that it will suit the purposes of the manipulator. Whichever the case, knowing the common flawed arguments will help students to be alert to flawed argumentation.

Argumentation theorists identify many types of flawed reasoning (Ivin 2007, Walton 2006, 2008, Walton, Reed, and Macagno 2008, Eemeren and Grootendorst 1992, Eemeren 2010) that can be grouped according to their nature. One very important group of flaws relates to the way language is used.

The language flaws include the use of emotive language, loaded terms, vague concepts that can be interpreted in many ways. The use of loaded terms and emotive language is one of the main techniques employed by people in modern post-truth reality. Emotive language use words that make us respond in an emotional way. As people tend to trust their emotions, it is particularly important to choose the right wording especially if the topics of the communication are emotive, such as national pride, religion, parents, motherland etc. Thus, it is important to develop in students language sensitivity, to attract their attention to emotive language, to teach them to choose the proper words.

\section{CONCLUSION}

Taking everything into consideration, it is important to underlie the importance of including argumentative practices into ESP courses. The ability to present one's own ideas in a logical orderly way, to support the opinion with proper and correctly build arguments, to recognize flaws in other people's argumentation are the basics of argumentative literacy and also are useful and practical skills that might be of great help in all spheres of life: academic, professional, social, private. Moreover, it might help to make more informed decisions. The ability to identify flaws in other people's arguments might help to formulate better counterarguments and what is more important to avoid being manipulated by other people whether they manipulate you deliberately or not. 


\section{REFERENCES}

Cottrell, Stella. Critical Thinking Skills. Palgrave Macmillan, 2011.

Common European Framework of Reference for Languages: Learning, Teaching, Assessment. Council of Europe. Strasbourg, 2001.

Dudley-Evans, Tony. Developments in English for Specific Purposes: A multi- disciplinary approach. Cambridge: Cambridge University Press, 1998.

Eemeren, Frans. van H., Peter Houtlosser, Francisca Henkemans. Argumentative Indicators in Discourse. Springer 2007

Eemeren Frans. van H., Rob Grootendorst. Argumentation, Communication, and Fallacies. A Pragma-Dialectical Perspective. Hillsdale, New Jersey: Lawrence Erlbaum Associates 1992

Eemeren Frans.van H. Strategic Maneuvering in Argumentative Discourse. Amsterdam: John Benjamin Publishing Company. 2010.

Goudkova K., Tretyakova T. The matrix for argumentation literacy in 21 century Russian education Proceedings of the $8^{\text {th }}$ International Conference of the International Society for the Study of Argumentation. Sit Sat. Amsterdam. 498-505

Harmer Jeremy. How to Teach English Pearson Longman 2007

Ivin Alexander. Logic and Argumentation Theory. Moscow: Gardariki, 2007.

Walton Douglas. The New Dialectic. Conversational Contexts of Argument. Toronto: University of Toronto Press. 1998.

Walton Douglas. Fundamentals of Critical Argumentation. NY: Cambridge University Press, 2006.

Walton, Douglas, Chris Reed and Fabrizio Macagno, Argumentation Schemes. Cambridge: Cambridge University Press. 2008.

Rybacki Karyn and Donald Rybacki. Advocacy and Opposition. An Introduction to Argumentation. Englewood Cliffs, New Jersey: Prentice Hall. 1991 